\title{
An Unusual Presentation of a Patient with Leg Ulcers: A Case Report
}

\author{
Sana Zafar ${ }^{1}$, Khurram Saleem $^{1}$, Aqeela Rashid ${ }^{2,1}$ \\ 1. Internal Medicine, University College of Medicine, University of Lahore, Lahore, PAK 2. Internal Medicine, Jinnah \\ Hospital, Allama Iqbal Medical College, Lahore, PAK
}

Corresponding author: Sana Zafar, silentwhispper@gmail.com

\begin{abstract}
Leg ulcers have been a common presentation in clinics; disruptions in the mechanism of ulcer healing are vascular insufficiency, anemia, metabolic disturbances, neuropathy, and autoimmunity. The term 'nontransfusion-dependent thalassemia' encompasses the milder forms of thalassemia traits that require intermittent or no transfusion at all, and are mostly associated with leg ulcers.
\end{abstract}

We present the case of a 19-year-old female with beta-thalassemia major who presented with non-healing leg ulcers and anemia. The clinical findings and lab evidence suggested hemolytic anemia evidenced by pathologic fractures, hepato-splenomegaly, and normal iron studies. Hemoglobin electrophoresis confirmed beta-thalassemia major with its complications including adrenal insufficiency and pathological fractures, all of which remained well compensated till the second decade of life.

Categories: Internal Medicine, Hematology

Keywords: leg ulcers, anemia, thalassemia major, non transfusion dependent

\section{Introduction}

Chronic lower limb ulceration is a frequently encountered presentation in clinical settings, with significant morbidity and psycho-social impact. affects about $1 \%$ of the adult population and $3.6 \%$ of people older than 65 years [1]. The causes of leg ulcers are multifactorial, the most common being venous insufficiency, arterial insufficiency, neuropathy, and diabetes. Indolent, non-healing ulcers are a feature of sickle cell disease, thalassemia, and other hemolytic anemias. Disruption of microvascular circulation is the underlying mechanism in such cases. Thrombotic and occlusive disease, for instance, antiphospholipid antibody syndrome, protein $\mathrm{C}$ and protein $\mathrm{S}$ deficiency, and cryoglobulinaemia also cause skin necrosis leading to ulceration and gangrene [2]. Here we present an unusual case of a young female with non-healing leg ulcers and anemia.

Received 11/03/2019

Review began 11/22/2019 Review ended 12/01/2019 Published 12/05/2019

\section{(c) Copyright 2019}

Zafar et al. This is an open access article distributed under the terms of the Creative Commons Attribution License CC-BY 3.0., which permits unrestricted use, distribution, and reproduction in any medium, provided the original author and source are credited.

\section{Case Presentation}

A 19-year-old female presented with a history of exertional shortness of breath, palpitations, dizziness for one and a half years, which had gradually worsened over a period of one month. The associated symptoms included left-sided upper abdominal heaviness, early satiety, easy bruising, joint pains, oral ulcers, and bone pains. She presented with recurrent ulcers on the legs and ankle requiring multiple antibiotics and visits to surgical clinics for the past three years. Her parents had a consanguineous marriage; in the past, she also had a spontaneous/pathological fracture of the right femur, which was treated but no medical record was available. There was no history of fever, significant blood loss, blood transfusions, lead exposure, early morning dark colored urine, loose stools, vomiting, abdominal pain, lumps and bumps, or prolonged history of drug intake.

Examination findings were as follows: pallor, hepato-splenomegaly, no lymphadenopathy. There were short systolic flow murmurs heard along the left sternal edge. In the lower limbs, the right leg showed a healed ulcer on the lateral malleolus. On the left leg, there was an approximately $10 \mathrm{~cm}$ elongated ulcer with undermined edges and pus at the base, along with surrounding skin excoriation and lichenification (Figure $1)$. 


\section{Cureus}

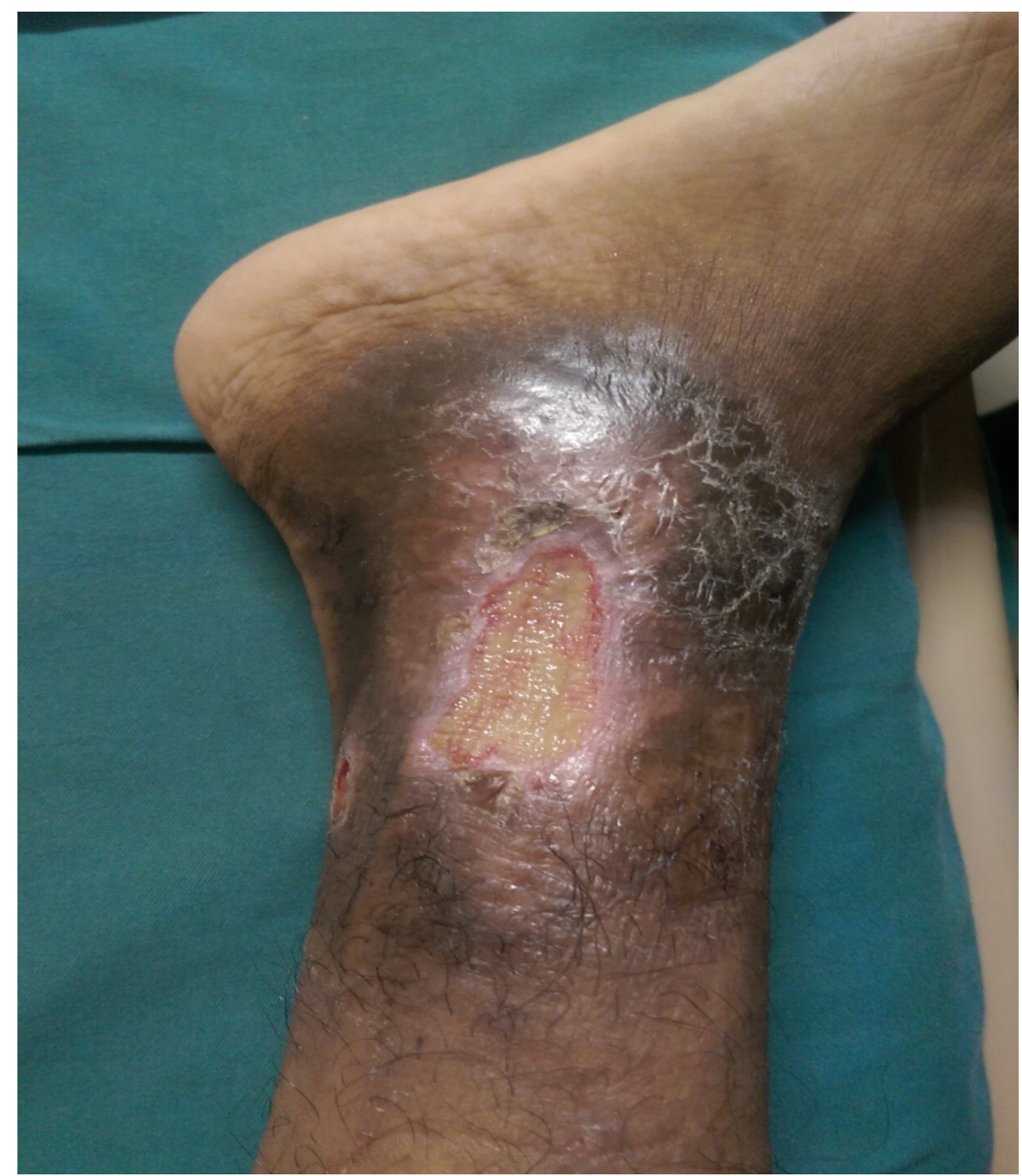

FIGURE 1: Leg ulcer (non healing)

Initial investigations were done as shown in Table 1. The results showed microcytic hypochromic anemia with normal iron studies. 


\section{Cureus}

\begin{tabular}{|c|c|c|}
\hline & 2018 & $\begin{array}{l}\text { Reference } \\
\text { Ranges }\end{array}$ \\
\hline Hemoglobin (g/dl) & 7.1 & $12-16$ \\
\hline Total leucocyte count ( $\left.{ }^{*} 10^{9} / \mathrm{L}\right)$ & 9.2 & $4-11$ \\
\hline Platelets $\left({ }^{*} 10^{9} / \mathrm{L}\right)$ & 575 & $150-450$ \\
\hline Mean corpuscular volume ( $(\mathrm{L}$ ) & 61 & 85-95 \\
\hline Mean corpuscular hemoglobin (pg) & 22 & 27-31 \\
\hline $\begin{array}{l}\text { Mean Corpuscular hemoglobin } \\
\text { concentration (pg/dl) }\end{array}$ & 32 & $32-38$ \\
\hline Peripheral blood smear & $\begin{array}{l}\text { Microcytic hypochromic RBCs, anisopoikilocytosis, tear drop cells, } \\
\text { target cells }\end{array}$ & \\
\hline Reticulocytes (\%) & 2.5 & $0.2-2.0$ \\
\hline Lactate dehydrogenase (u/l) & 317 & Upto 250 \\
\hline Iron ( $\mu \mathrm{g} / \mathrm{dl})$ & 300 & $65-175$ \\
\hline Ferritin (ng/ml) & 736.6 & Upto 280 \\
\hline Total Iron binding capacity $(\mu \mathrm{g} / \mathrm{dl})$ & 286 & $250-400$ \\
\hline Vitamin B12 (pg/ml) & 260 & $160-914$ \\
\hline Red cell folate $(\mathrm{ng} / \mathrm{ml})$ & 750 & $529-2322$ \\
\hline Bilirubin (mg/dl) & 2.3 & $0-1.2$ \\
\hline Alanine aminotransferase (U/L) & 23 & Up to 32 \\
\hline Aspartate aminotransferase (U/L) & 42 & Up to 32 \\
\hline Alkaline phosphatase (U/L) & 61 & $35-106$ \\
\hline
\end{tabular}

TABLE 1: Initial investigations showing microcytic hypochromic anemia

For the workup of the leg ulcer, she underwent an incisional biopsy of the leg ulcer which showed chronic granulomatous inflammation with no evidence of malignancy; periodic acid-Schiff (PAS) stain was negative for fungus. Lower gastrointestinal (GI) endoscopy was done for the possibility of inflammatory bowel disease but colonoscopy showed normal mucosa with normal haustration pattern. Doppler studies of the lower limbs showed normal arterial and venous flow. Magnetic resonance imaging (MRI) of the left leg showed multiple hyper-intense signals in the tibia, calcaneus and talus with no evidence of osteomyelitis. Furthermore, autoimmune workup and vasculitis screen was done as shown in Table 2 . 


\section{Cureus}

\begin{tabular}{|c|c|c|}
\hline & Patient's Value & Reference Range \\
\hline ANA & Nucleolar pattern 1:100 & $<1: 100$ \\
\hline anti-dsDNA (IU/ml) & 83 & $>25$ (positive) \\
\hline RA factor (IU/ml) & $<20.0$ & $>50.0$ (positive) \\
\hline Complement C3 (mg/dL) & 123 & 83-193 \\
\hline C4 (mg/dL) & 30.1 & $15-57$ \\
\hline c-ANCA & 0.62 & >1.10 (positive) \\
\hline p-ANCA & 0.78 & $>1.10$ (positive) \\
\hline
\end{tabular}

\section{TABLE 2: Autoimmune workup}

Anti-dsDNA: anti-double-stranded deoxyribonucleic acid; RA factor: rheumatoid factor; ANCA: antineutrophil cytoplasmic antibodies.

She was prescribed oral steroids by the dermatology team considering the diagnosis of ANCA negative vasculitis (leucocytoclastic angiitis) which showed no improvement during her hospital admission. Hemoglobin electrophoresis was done and it supported her clinical condition to reach the final diagnosis of thalassemia major. The results are shown below (Table 3).

\begin{tabular}{|c|c|c|}
\hline & Patient's value & Reference range \\
\hline HBA & $12 \%$ & $96.5-99.5 \%$ \\
\hline $\mathrm{HBA}_{2}$ & $1.9 \%$ & $0-3.5 \%$ \\
\hline $\mathrm{HBF}$ & $86.1 \%$ & $<2 \%$ (age dependent) \\
\hline
\end{tabular}

\section{TABLE 3: Hemoglobin electrophoresis}

HBA: hemoglobin A; HBF: hemoglobin F.

The patient was diagnosed as a case of beta-thalassemia major, which remained non-transfusion dependent up to the second decade of life. Radiographic findings suggestive of marrow cavity expansion were present as well. Another finding was a significant postural drop of blood pressure for which serum cortisol and adrenocorticotropic hormone (ACTH) levels were done, which were suggestive of adrenal insufficiency (Table 4).

\begin{tabular}{|c|c|c|}
\hline & Patient's value & Reference range \\
\hline Cortisol (9 AM) $\mu \mathrm{g} / \mathrm{dL}$ & 2.3 & 3.7-19.4 \\
\hline ACTH (pg/ml) & 68.4 & $9-52$ \\
\hline
\end{tabular}

\section{TABLE 4: Lab values suggesting adrenal insufficiency}

ACTH: adrenocorticotropic hormone.

The patient was transfused with packed red blood cells and hemoglobin was built up to $10 \mathrm{~g} / \mathrm{dL}$ along with ciprofloxacin, $500 \mathrm{mg}$ twice daily, for treatment of secondary wound infection. This resulted in complete wound healing (Figure 2). 


\section{Cureus}

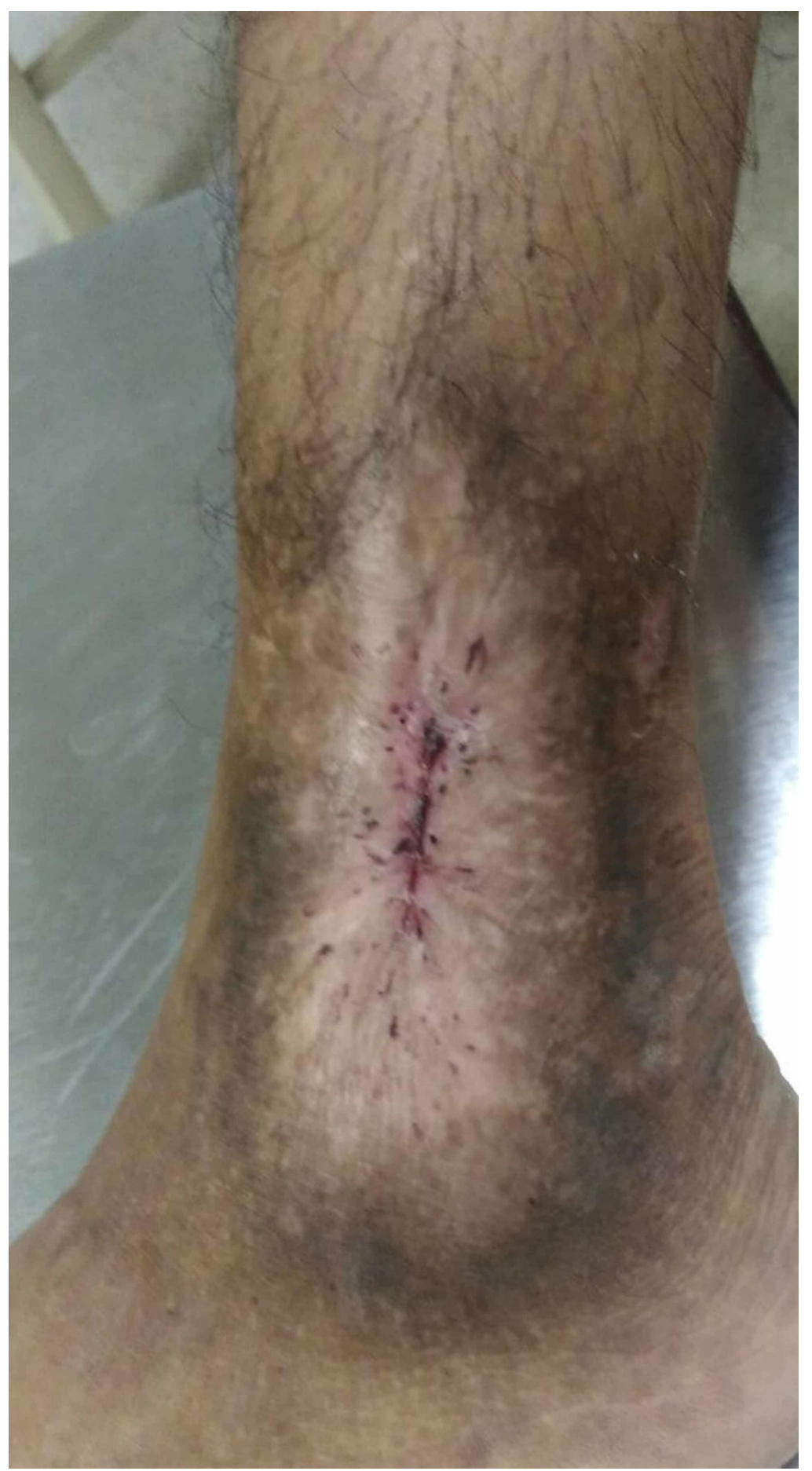

\section{FIGURE 2: Healed leg ulcer}

Also, daily replacement of oral steroids (prednisolone $5 \mathrm{mg}+2.5 \mathrm{mg}$ ) was given, which improved her symptoms of postural dizziness as noted on a follow-up visit. Oral iron chelation therapy, deferasirox was given to manage iron overload associated with thalssemia-related hemolysis and blood transfusions.

\section{Discussion}

Inherited hemoglobin disorders have been divided on the basis of defective chain synthesis ( $\alpha$ - and $\beta$ thalassemia) and structural variations (Hemoglobin S, C, and E). Various clinical presentations result from either simultaneous inheritance of two different mutations or their co-existence with structural variants. However, in all the cases, the result is defective red blood cell production, with peripheral hemolysis and anemia [3]. For this reason, transfusion dependence has been one of the essential factor in distinguishing the various thalassemia phenotypes and their severity. Figure 3 illustrates the different thalassemia traits according to the transfusion dependence. 


\section{Cureus}

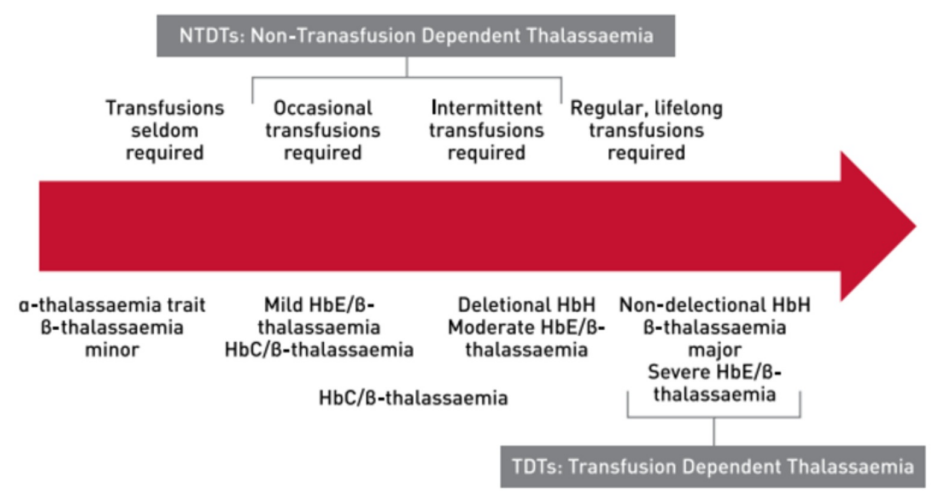

\section{FIGURE 3: Spectrum of thalassemia syndromes}

Image courtesy: Guidelines for the Management of Transfusion Dependent Thalassaemia (TDT) [4].

Patients with transfusion-dependent thalassemia (TDTs) require regular blood transfusion to survive. $\beta$ thalassaemia major, severe $\mathrm{HbE} / \beta$-thalassemia, non-deletional hemoglobin $\mathrm{H}(\mathrm{HbH})$ disease are included in this category. Non-transfusion-dependent thalassemia includes $\beta$-thalassemia intermedia, hemoglobin $\mathrm{E}$ $(\mathrm{HbE}) / \beta$-thalassemia, and $\mathrm{HbH}$ disease. This sub-group require seldom or intermittent transfusion according to the clinical stress [4].

With increasing age, the complications associated with thalassemia syndromes develop. These may be related to the transfusion dependency or a part of the disease itself. These include secondary hemosiderosis, endocrine abnormalities, bone disease, pathological fractures, and hemodynamic changes. The development of pulmonary hypertension and cardiac arrhythmias can be fatal. Adequate physician education and understanding is required to preempt the complications and diagnose them earlier in the course of the disease. Figure 4 represents the commonly encountered complications of thalassemia as per their transfusion dependence [5]. 


\section{Cureus}

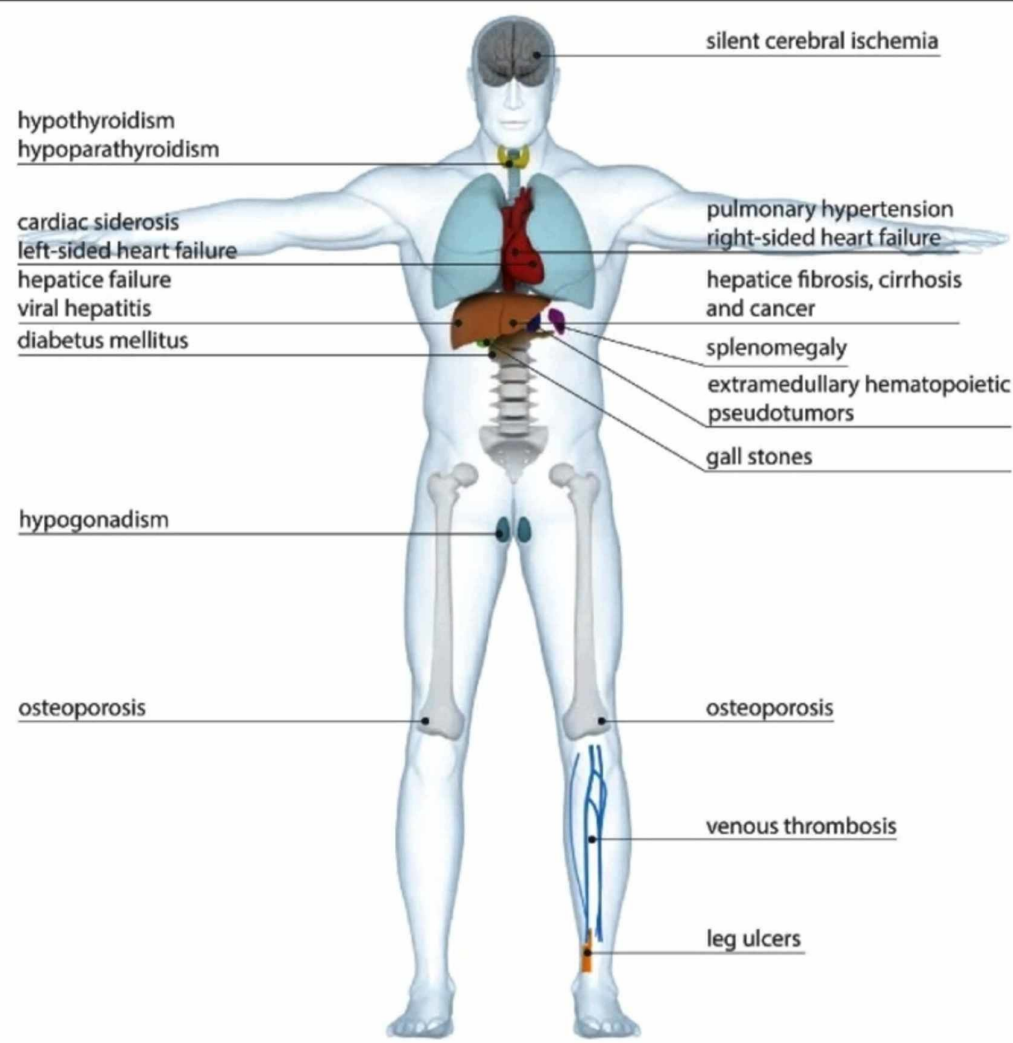

\section{FIGURE 4: Complications of transfusion-dependent and non- transfusion-dependent thalassemia major}

Image courtesy: Non-transfusion-dependent thalassemias [3].

The association of leg ulcers has been observed more in patients of non-transfusion dependent thalassemia, especially in the elderly. This is because of the increased skin and vascular fragility in the elderly, due to reduced oxygen supply at the peripheries. Consequently, they have an increased risk of developing leg ulcers after minimal trauma [6]. Local iron deposition is also considered to be a contributing factor in poor healing of leg ulcers especially when heme component of the red blood cells deposits locally giving a dark hue. Thus higher rates of leg ulcers have been reported in patients with a non-transfusion-dependent spectrum of the disease having iron overload [6].

However, our patient's case was an unusual presentation of beta-thalassemia major, who remained wellcompensated up till the second decade of life without any blood transfusions. Rather she presented with complications of the disease in the form of leg ulcers, adreno-cortical insufficiency and pathological fractures.

\section{Conclusions}

Thalassemia is a hemoglobinopathy with a spectrum of clinical presentations. Although thalassemia major presents earlier in life with resultant dependence on blood transfusion in the first few years of life, there can be a variability in the presentation, as in our patient who presented with recurrent leg ulcers and features of anemia and remained well-compensated until the adolescent age when the need for regular transfusions arise.

\section{Additional Information}

\section{Disclosures}

Human subjects: Consent was obtained by all participants in this study. University of Lahore Teaching Hospital issued approval --. Informed consent has been taken from the subject involved in case study. . Conflicts of interest: In compliance with the ICMJE uniform disclosure form, all authors declare the following: Payment/services info: All authors have declared that no financial support was received from 


\section{Cureus}

any organization for the submitted work. Financial relationships: All authors have declared that they have no financial relationships at present or within the previous three years with any organizations that might have an interest in the submitted work. Other relationships: All authors have declared that there are no other relationships or activities that could appear to have influenced the submitted work.

\section{References}

1. Puri N, Talwar A: Etiology and management of leg ulcers - an enigma . J Pak Ass Dermatologists. 2015, 25:211-215.

2. Sarkar PK, Ballantyne S: Management of leg ulcers. Postgrad Med J. 2000, 76:674-682. 10.1136/pmj.76.901.674

3. Musallam MK, Rivella S, Vichinsky E, Rachmilewitz AE: Non-transfusion-dependent thalassemias. Hematologica. 2013, 98:833-844. 10.3324/haematol.2012.066845

4. Viprakasit V, Origa R, Fucharoen S: Genetic basis, pathophysiology and diagnosis. Guidelines for the Management of Transfusion Dependent Thalassaemia (TDT). Cappellini MD, Cohen A, Porter J, et al. (ed): Thalassaemia International Federation, Nicosia; 2014. 14-26.

5. Motta I, Mancarella M, Marcon A, Vicenzi M, Cappellini MD: Management of age-associated medical complications in patients with $\beta$-thalassemia. Expert Rev Hematol. 2019, https://doi.org/10.1080/17474086.2020.1686354

6. Taher A, Musallam K, Cappellini MD: Leg ulcers. Guidelines for the Management of Transfusion Dependent Thalassaemia (TDT). Taher A, Musallam K, Cappellini MD (ed): Thalassaemia International Federation, Nicosia; 2017. 100-103. 